\title{
PENGARUH KUALITAS PRODUK, MERK, DAN HARGA TERHADAP KEPUTUSAN PEMBELIAN SEPEDA MOTOR HONDA SCOOPY PADA PT. ASTRA INTERNASIONAL HONDA SALES OPERATIONS TbK. HONDA CABANG DENPASAR
}

\author{
Dewa Ayu Putri Krisna Dewi ${ }^{1}$ \\ I Gusti Gede Purwa Sudarta ${ }^{2}$ \\ ${ }^{1,2}$ Fakultas Ekonomi Universitas Ngurah Rai
}

\begin{abstract}
ABSTRAK
Tujuan penelitian ini untuk mengetahui pengaruh kualitas produk, merk, dan harga secara parsial dan pengaruh kualitas produk, merk, dan harga secara simultan di PT. Astra Internasional Honda Sales Operations Tbk Honda Cabang Denpasar dengan 99 responden dalam penelitian ini. Pengumpulan data dengan menyebarkan kuesioner. Berdasarkan analisis, maka diperoleh kesimpulan bahwa 1) Dari hasil analisis regresi linier berganda diperoleh persamaan regresi $Y=4,734+0,223 X_{1}+0,262 X_{2}+0,347$ $\mathrm{X}_{3}$. Ini menunjukkan adanya pengaruh positif dan signifikan antara kualitas produk, merk, dan harga terhadap keputusan pembelian. 2) Berdasarkan hasil T-test diperoleh bahwa harga mempunyai pengaruh yang lebih kuat dibandingkan dengan kualitas produk dan merk, ditunjukkan oleh nilai thitung terbesar dibandingkan variabel lainnya yaitu sebesar, 2,916 dengan signifikan 0,004. 3) Dari hasil analisis F-test diperoleh bahwa sig. F adalah 0,000 lebih kecil dari 0,05 ini berarti bahwa kualitas produk, merk, dan harga terhadap keputusan pembelian secara simultan berpengaruh signifikan.
\end{abstract}

Kata kunci : Kualitas Produk, Merk, Harga

\begin{abstract}
The purpose of this study to determine the effect of product quality, brands, and prices partially and influence the quality of products, brands, and prices simultaneously in PT. Astra Internasional Honda Sales Operations Tbk Honda Branch Denpasar with 99 respondents in this research. Data collection by distributing questionnaires. Based on the analysis, then obtained the conclusion that 1) From the results of multiple linear regression analysis obtained regression equation $Y=4.734+0.223 X 1+$ $0.262 X 2+0.347 X 3$. This indicates a positive and significant influence between product quality, brand, and price on purchasing decisions. 2) Based on T-test results obtained that the price has a stronger influence compared to product and brand quality, indicated by the largest t-count value compared to other variables that is equal to, 2.916 with significant 0.004. 3) From the results of F-test obtained that sig. $F$ is 0.000 smaller than 0.05 this means that product quality, brand, and price to purchase decision simultaneously have a significant effect.
\end{abstract}

Keywords: Product Quality, Brand, Pric 


\section{PENDAHULUAN}

Pertumbuhan ekonomi yang semakin meningkat, dengan semakin pesatnya perkembangan dunia usaha, ditandai dengan banyak berdirinya perusahaan dan berkembangnya perusahaan yang ada, baik yang bergerak dibidang industri, perdagangan maupun jasa. Keadaan tersebut menimbulkan persaingan yang semakin kompetitif diantara perusahaan. Dalam usaha menghadapi persaingan yang semakin ketat maka perusahaan harus mampu meningkatkan mutu dan kualitas pelayanannya. Sebuah perusahaan akan hidup bila memiliki konsumen. Oleh karena itu konsumen merupakan yang menyebabkan perusahaan itu ada. Kepuasan dari konsumen merupakan hal penting yang harus menjadi prioritas dari sebuah perusahaan, Dengan memahami kebutuhan, keinginnan dan harapan para konsumen, akan memudahkan bagi suatu perusahaan untuk memenangkan persaingan yang semakin ketat.

Selain itu terciptanya kepuasan konsumen juga dapat menyebabkan terjadinya hubungan yang harmonis antara perusahaan dan konsumennya, memberikan dasar yang baik bagi pembelian ulang, menciptakan loyalitas konsumen serta membentuk suatu rekomendasi dari mulut ke mulut (word of mouth) yang menguntungkan bagi perusahaan (Fandy Tjiptono, 2000 :24).

Agar perusahaan mampu bersaing dan dapat memberikan pelayanan yang maksimal maka perusahaan harus dapat mendesain layanan yang lebih unggul dari pada pesaing, yang sesuai dengan harapan konsumen agar konsumen tidak beralih pada perusahaan pesaing sehingga nantinya akan dapat menciptakan loyalitas konsumen dan konsumen bersedia untuk melakukan pembelian ulang.

Saat ini diyakini bahwa kunci utama untuk memenangkan persaingan adalah dengan memahami serta memuaskan keinginan dan kebutuhan konsumen melalui penyampaian produk dan jasa yang berkualitas dan harga bersaing. Perusahaan harus mengerahkan semua upaya dalam memenuhi kebutuhan konsumen agar dapat memperoleh laba yang merupakan tujuan dari setiap perusahaan. Bila konsumen puas atas pelayanan yang diperoleh, maka akan tercipta suatu hubungan yang harmonis antara perusahaan dengan konsumen.

Bagi pengguna sarana jalan raya, kendaraan bermotor baik roda dua maupun roda empat sebagai salah satu sarana transportasi, memegang peranan penting dalam kehidupan masyarakat terutama dalam era globalisasi ini manusia dituntut untuk memiliki mobilitas yang tinggi untuk dapat berinteraksi dengan sesamanya. Industri otomotif merupakan salah satu industri yang berkembang pesat di Indonesia selama kurun waktu terakhir ini. Hal ini sangat tidak mengherankan sebab perkembangannya ditunjang oleh laju pertumbuhan penduduk dan 
meningkatnya kebutuhan masyarakat Indonesia akan sarana transportasi dari waktu ke waktu. Selain disebabkan oleh laju pertumbuhan, terjadinya peningkatan pendapatan menyebabkan meningkatnya daya beli konsumen, untuk memilih sepeda motor pilihan keluarga. Dengan semakin meningkatnya pasar industri otomotif di Indonesia, dapat dilihat dari begitu pesatnya perkembangan produsen sepeda motor yang menawarkan berbagai merk dengan kualitas, kelas, dan keunggulan-keunggulan tersendiri serta dengan jaringan pasar yang makin meluas ke seluruh penjuru dunia. Bagi perusahaan yang bergerak di bidang industri otomotif seperti PT. Astra International HSO Tbk. - Honda Cabang Denpasar, kebutuhan konsumen akan sepeda motor kian meningkat dari tahun ke tahun merupakan suatu peluang bagi pemasaran produk - produknya.

Dengan banyaknya usaha bisnis yang serupa bermunculan, tentunya akan menjadi persaingan semakin ketat. Dalam perusahaan perlu adanya seorang pemimpin yang tanggap dengan keadaan ini. Diharapkan ia akan dapat mengatasi permasalahan yang ada dengan suatu perencanaan strategi pemasaran yang tepat agar perusahaan yang dipimpinnya dapat mengantisipasi perubahan yang terjadi baik dari dalam maupun dari luar perusahaan, sehingga kelangsungan hidup perusahaan dapat terus berlanjut. Persaingan tidak dapat lagi dihindari apalagi dihilangkan oleh setiap perusahan yang bersaing dalam dunia bisnis, dimana persaingan semakin ketat. Setiap perusahaan akan berusaha untuk menenangkan persaingan agar dapat mempertahankan kontinuitas dalam jangka panjang. Apalagi persaingan dewasa ini sedang menyambut datangnya era perdagangan bebas yang ditandai dengan semakin ketatnya persaingan di sektor bisnis.

Strategi pemasaran berupaya untuk memberikan keuntungan jangka panjang serta dapat menjaga kestabilan usaha maupun menjamin kehidupan perusahaan di masa yang akan datang. Pemasaran sangat penting dalam mencapai tujuan perusahaan guna memperoleh pendapatan.

Perilaku pembelian konsumen dipengaruhi oleh rangsangan pemasaran, rangsangan lingkungan dan karakteristik dari pembeli. Produk, harga, promosi dan distribusi yang menarik, sehingga konsumen memutuskan untuk membeli termasuk rangsangan pemasaran, sedangkan yang meliputi rangsang lingkungan yaitu keadaan ekonomi, politik, sosial dan budaya.Yang termasuk karakteristik pembeli adalah faktor budaya, faktor sosial, faktor pribadi, dan faktor psikologis. Faktor budaya terbentuk atas budaya, sub budaya, dan kelas sosial. Faktor sosial terdiri atas usia, tahap siklus hidup, pekerjaan, lingkungan ekonomi, gaya hidup, kepribadian dan konsep diri. Faktor psikologis dikategorikan atas motivasi, persepsi, pendidikan keyakinan dan sikap. Perusahaan perlu mengetahui dan mempelajari perilaku konsumen, karena dengan diketahuinya perilaku konsumen perusahaan akan dapat merumuskan kebijakan atau strategi yang tepat untuk mencapai target penjualan ini 
mendorong penulis untuk mengadakan penelitian tentang keputusan pembelian, dalam hal ini mereka yang melakukan pembelian produk sepeda motor Honda Scoopy pada PT. Astra International HSO Tbk. - Honda Cabang Denpasar. Honda Scoopy merupakan salah satu produk yang ditawarkan PT. Astra International HSO Tbk. - Honda Cabang Denpasar. Perbedaan dari tipe kendaran tersebut terletak pada varian warna dengan banyak pilihan warna yang stylish. Perbedaan warna ini dimaksudkan untuk lebih memuaskan konsumen dan menciptakan suatu sepeda motor pilihan keluarga yang nyaman, serta memberikan beragam pilihan kepada para konsumen.

Didalam penelitian ini yang menjadi masalah dari ketiga variabel yaitu kualitas produk, merk, dan harga adalah kualitas produk, karena saat konsumen melakukan service pada PT. Astra Internasional HSO. Tbk Honda Cabang Denpasar konsumen tidak merasa puas dengan pelayanan service yang dilakukan. Pada saat service selesai salah satu dari konsumen menyata bahwa kualitas dari tarikan mesin sepeda motor scopy khususnya pada jalan tanjakkan tidak maksimal

\section{Rumusan Masalah}

Berdasarkan latar belakang masalah di atas maka yang menjadi rumusan masalah dalam penelitian ini adalah :

1. Bagaimanakah pengaruh kualitas produk, merk dan harga secara parsial terhadap keputusan pembelian sepeda motor Honda Scoopy pada PT. Astra Internasional HSO Tbk.- Honda Cabang Denpasar?

2. Bagaimanakah pengaruh kualitas produk, merk dan harga secara simultan terhadap keputusan pembelian sepeda motor Honda Scoopy pada PT. Astra Internasional HSO Tbk.- Honda Cabang Denpasar?

\section{METODE PENELITIAN}

Penelitian ini dilakukan pada konsumen dengan mengambil data yang pasti pada dealer Honda PT Astra International HSO Tbk. Honda Cabang Denpasar yang berlokasi di HSO Cokroaminoto No. 80 Denpasar, karena adanya masalah mengapa konsumen lebih memilih sepeda motor Honda Scoopy. Sepeda motor Honda Scoopy menawarkan berbagai macam varian warna yang menarik. Selain itu Honda Scoopy merupakan sepeda motor yang sangat irit dan mudah untuk dilakukan perawatan dan harganyapun terbilang mudah dijangkau masyarakat luas.

Pada penelitian ini menggunakan teknik analisis data regresi linier berganda, uji T-test dan uji F-test.

\section{HASIL DAN PEMBAHASAN}

Teknik analisis regresi linear berganda ini digunakan untuk meramalkan bagaimana variabel dependen dipengaruhi oleh variabel independen. Analisis ini dilakukan apabila jumlah variabel independennya minimal dua. Dalam penelitian ini yaitu pengaruh kualitas produk (X1), merk (X2) dan harga (X3) terhadap pembelian sepeda motor Honda Scoopy (Y) pada PT Astra International HSO Tbk. Honda Cabang Denpasar yang berlokasi di HSO Cokroaminoto No. 80 Denpasar, dapat dilihat pada tabel 1 dibawah ini 
Pengaruh Kualitas Produk, Merk, dan Harga Terhadap Keputusan Pembelian Sepeda Motor Honda Scoopy Pada PT. Astra Internasional Honda Sales Operations Tbk. Honda Cabang

Denpasar

Tabel 5.1 Analisis Regresi Linier Berganda

Coefficients $^{\mathrm{a}}$

\begin{tabular}{|c|c|c|c|c|c|}
\hline \multirow[b]{2}{*}{ Model } & \multicolumn{2}{|c|}{$\begin{array}{l}\text { Unstandardized } \\
\text { Coefficients }\end{array}$} & $\begin{array}{c}\text { Standardize } \\
\text { d } \\
\text { Coefficient } \\
\text { s } \\
\end{array}$ & & \multirow[b]{2}{*}{ Sig. } \\
\hline & $\mathrm{B}$ & Std. Error & Beta & $\mathrm{T}$ & \\
\hline $1 \quad$ (Constant) & 4,734 & 1,759 & & 2,691 &, 008 \\
\hline $\begin{array}{l}\text { KUALITAS_PRO } \\
\text { DUK }\end{array}$ & ,223 &, 114 & , 198 & 1,953 &, 054 \\
\hline MERK & ,262 &, 128 & ,212 & 2,051 & ,043 \\
\hline HARGA & ,347 & 119 & ,289 & 2,916 &, 004 \\
\hline
\end{tabular}

Berdasarkan tebel diatas hasil persamaan regresi linier dapat dijelaskan sebagai berikut :

$$
\begin{aligned}
& \mathrm{Y}=\mathrm{a}+\beta 1 \mathrm{X} 1+\beta 2 \mathrm{X} 2+\beta 3 \mathrm{X} 3 \\
& \mathrm{Y}=4,734+0,223 \mathrm{X}_{1}+0,262 \mathrm{X}_{2}
\end{aligned}
$$

$+0,347 \mathrm{X}_{3}$

Dari persamaan diatas dapat dijelaskan bahwa pengaruh kualitas produk $\left(\mathrm{X}_{1}\right)$, merk $\left(\mathrm{X}_{2}\right)$, harga $(\mathrm{X} 3)$, keputusan pembelian (Y) yaitu sebagai berikut:

$\mathrm{a}=$ sebesar 4,734 artinya jika kualitas produk $\left(\mathrm{X}_{1}\right)$ merk $\left(\mathrm{X}_{2}\right)$ dan harga $\left(\mathrm{X}_{3}\right)$ tidak mengalami perubahan atau tetap, maka keputusan pembelian (Y) sepeda motor Scoopy pada PT. Astra International HSO Cabang Denpasar sebesar 4,734.

$\mathrm{b}_{1}=$ sebesar 0,223 berarti apabia kualitas produk $\left(\mathrm{X}_{1}\right)$ dinaikkan satu kesatuan (1) merk $\left(\mathrm{X}_{2}\right)$ dan harga $\left(\mathrm{X}_{3}\right)$ tidak berubah maka maka keputusan pembelian (Y) naik sebesar 0,223 satuan. Hal ini menjelaskan bahwa kualitas produk berpengaruh positif terhadap keputusan pembelian. Jika kualitas produk semakin baik maka semakin meningkat juga keputusan pembelian sepeda motor Honda Scoopy pada PT. Astra International HSO - Cabang Denpasar.

$\mathrm{b}_{2}=$ sebesar 0,262 berarti apabila merk $\left(\mathrm{X}_{2}\right)$ dinaikkan satu kesatuan (1) dan kualitas produk $\left(\mathrm{X}_{1}\right)$ tidak berubah maka keputusan pembelian (Y) meningkat sebesar 0,262 satuan. Hal ini menjelaskan bahwa merk berpengaruh positif terhadap keputsan pembelian.

$\mathrm{b}_{3}=$ sebesar 0,347 berarti apabila harga $\left(\mathrm{X}_{3}\right)$ dinaikkan satu kesatuan (1) dan kualitas produk $\left(\mathrm{X}_{1}\right)$ tidak berubah maka keputusan pembelian (Y) meningkat sebesar 0,347 satuan. Hal ini menjelaskan bahwa harga berpengaruh positif terhadap keputsan pembelian.

Dengan pernyataan diatas berarti apabila variabel kualitas produk, merk, dan harga meningkat, maka akan meningkat pula keputusan pembelian pada PT. Astra 
International HSO - Cabang Denpasar.

\section{Analisis Uji T ( Uji Hipotesis Secara Parsial )}

Uji $t$ (test of significance individual parameter) digunakan untuk mengetahui pengaruh signifikan yang diberikan oleh variabel bebas yaitu kualitas produk, merk, dan harga terhadap variabel terikat, yaitu kepuasan konsumen secara parsial.

Tabel 5.5 Hasil Uji T

\begin{tabular}{|c|c|c|c|c|c|}
\hline \multicolumn{6}{|c|}{ Coefficients $^{a}$} \\
\hline \multirow[b]{2}{*}{ Model } & \multicolumn{2}{|c|}{$\begin{array}{c}\text { Unstandardized } \\
\text { Coefficients }\end{array}$} & \multirow{2}{*}{$\begin{array}{c}\begin{array}{c}\text { Standardized } \\
\text { Coefficients }\end{array} \\
\text { Beta }\end{array}$} & \multirow[b]{2}{*}{$\mathrm{T}$} & \multirow[b]{2}{*}{ Sig. } \\
\hline & $\mathrm{B}$ & Std. Error & & & \\
\hline $1 \quad$ (Constant) & 4,734 & 1,759 & & 2,691 & ,008 \\
\hline KUALITAS_PRODUK & ,223 &, 114 & , 198 & 1,953 & ,054 \\
\hline MERK & ,262 & , 128 & ,212 & 2,051 & ,043 \\
\hline HARGA & ,347 &, 119 & ,289 & 2,916 & ,004 \\
\hline
\end{tabular}

1. Pengaruh kualitas produk terhadap pembelian sepeda motor Honda Scoopy pada PT. Astra International HSO Cabang Denpasar.

Langkah-langkah pengujian hipotesis adalah sebagai berikut:

a. Perumusan hipotesis

$\mathrm{H}_{0}: \beta \mathrm{i}=0$ berarti tidak ada pengaruh yang signifikan antara kualitas produk (X1), merk (X2) dan harga (X3) terhadap pembelian sepeda motor Honda Scoopy (Y) pada Honda Scoopy pada PT. Astra International HSO - Cabang Denpasar

Hi : $\beta \mathrm{i}>0$ berarti ada pengaruh yang signifikan secara parsial antara kualitas produk (X1), merk (X2) dan harga (X3) terhadap pembelian sepeda motor Honda Scoopy pada PT. Astra International HSO Cabang Denpasar.

Sesuai dengan hipotesis alternative ( $\mathrm{Hi}$ ) yang diajukan di atas, maka dalam pengujian ini digunakan uji sisi kanan dengan $\alpha=0,05$ dan $\mathrm{df}=\mathrm{n}-\mathrm{k}-1$.

b. Membandingkan nilai t-hitung dengan nilai t-tabel, dengan kriteria sebagai berikut :

1) Jika t-hitung $\leq$ t-tabel, maka $\mathrm{H}_{0}$ diterima dan Hi ditolak.

2) Jika t-hitung > t-tabel, maka $\mathrm{H}_{0}$ ditolak dan Hi diterima.

c. Perhitungan t-hitung

d. Berdasarkan gambar penerimaan dan penolakan Ho diatas ditentukan, nilai t hitung $=1,953$ lebih besar dari $\mathrm{t}$ tabel 1,661 
Pengaruh Kualitas Produk, Merk, dan Harga Terhadap Keputusan Pembelian Sepeda Motor Honda Scoopy Pada PT. Astra Internasional Honda Sales Operations Tbk. Honda Cabang

Denpasar

dengan nilai signifikasi $=0,054$ lebih kecil dari 0,05 sehingga $\mathrm{Ho}$ ditolak dan $\mathrm{Ha}$ diterima. Ini berarti bahwa kualitas produk $\left(\mathrm{X}_{1}\right)$ konstan, secara statistika pada taraf kepercayaan 5\%, maka kualitas produk $\left(\mathrm{X}_{1}\right)$ berpengaruh positif dan signifikan terhadap keputusan pembelian (Y). Berartinya kualitas produk merupakan peran penting dalam meningkatkan penjualan sepeda motor Honda Scoopy pada PT. Astra International HSO Cabang Denpasar.

e. Menggambarkan daerah penerimaan dan penolakan hipotesis. Untuk mengetahui bahwa H0 diterima atau ditolak, maka digambarkan dalam kurva distribusi t sebagai berikut :

\section{Gambar 5.1}

\section{Daerah Penerimaan dan Penolakan $\mathrm{H}_{0}$ (t-test uji $\beta 1$ )}

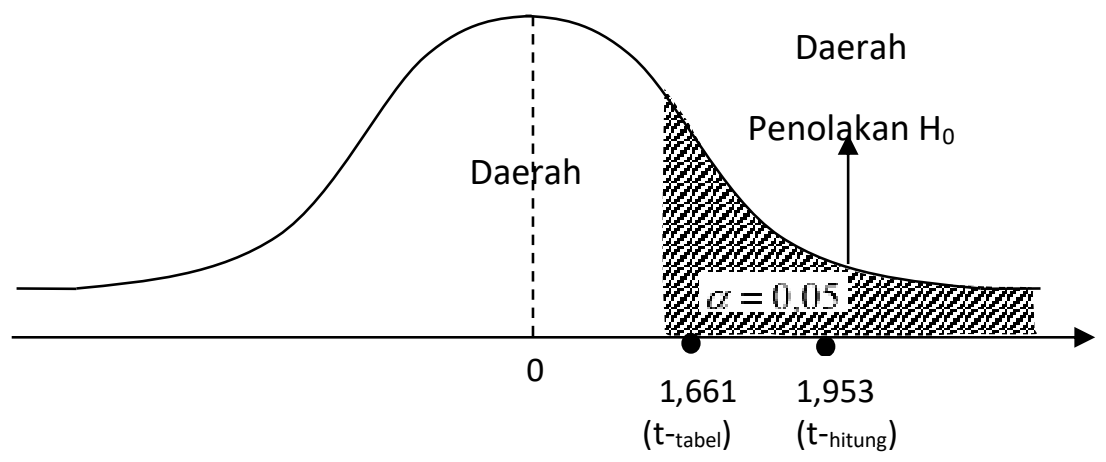

2. Pengaruh merk terhadap pembelian sepeda motor Honda Scoopy pada PT. Astra International HSO - Cabang Denpasar.

a. Perumusan hipotesis

$\mathrm{H}_{0}: \beta \mathrm{i}=0$ berarti tidak ada pengaruh yang signifikan antara kualitas produk (X1), merk (X2) dan harga (X3) terhadap pembelian sepeda motor Honda Scoopy (Y) pada Honda Scoopy pada PT. Astra International HSO - Cabang Denpasar

Hi : $\beta \mathrm{i}>0$ berarti ada pengaruh yang signifikan secara parsial antara kualitas produk (X1), merk (X2) dan harga (X3) terhadap pembelian sepeda motor Honda Scoopy pada PT. Astra International HSO Cabang Denpasar.

Sesuai dengan hipotesis alternative ( $\mathrm{Hi}$ ) yang diajukan di atas, maka dalam pengujian ini digunakan uji sisi kanan dengan $\alpha=0,05$ dan $\mathrm{df}=\mathrm{n}-\mathrm{k}-1$.

Membandingkan nilai t-hitung dengan nilai t-tabel, dengan kriteria sebagai berikut :

1) Jika t-hitung $\leq t$-tabel, maka $\mathrm{H}_{0}$ diterima dan Hi ditolak.

2) Jika t-hitung > t-tabel, maka $\mathrm{H}_{0}$ ditolak dan Hi diterima.

b. Perhitungan t-hitung 
c. Berdasarkan gambar penerimaan dan penolakan Ho diatas ditentukan, nilai t hitung $=2,051$ lebih besar dari $t$ tabel 1,661 dengan nilai signifikasi $=0,043$ lebih kecil dari 0,05 sehingga Ho ditolak dan $\mathrm{Ha}$ diterima. Ini berarti bahwa kualitas produk $\left(\mathrm{X}_{1}\right)$ konstan, secara statistika pada taraf kepercayaan 5\%, maka merk $\left(\mathrm{X}_{2}\right)$ berpengaruh positif dan signifikan terhadap keputusan pembelian (Y).
Berartinya merk merupakan peran penting dalam meningkatkan penjualan sepeda motor Honda Scoopy pada PT. Astra International HSO Cabang Denpasar.

d. Menggambarkan daerah penerimaan dan penolakan hipotesis. Untuk mengetahui bahwa H0 diterima atau ditolak, maka digambarkan dalam kurva distribusi t sebagai berikut :

Gambar 5.1.1

Daerah Penerimaan dan Penolakan $\mathrm{H}_{0}$ (t-test uji $\beta 2$ )

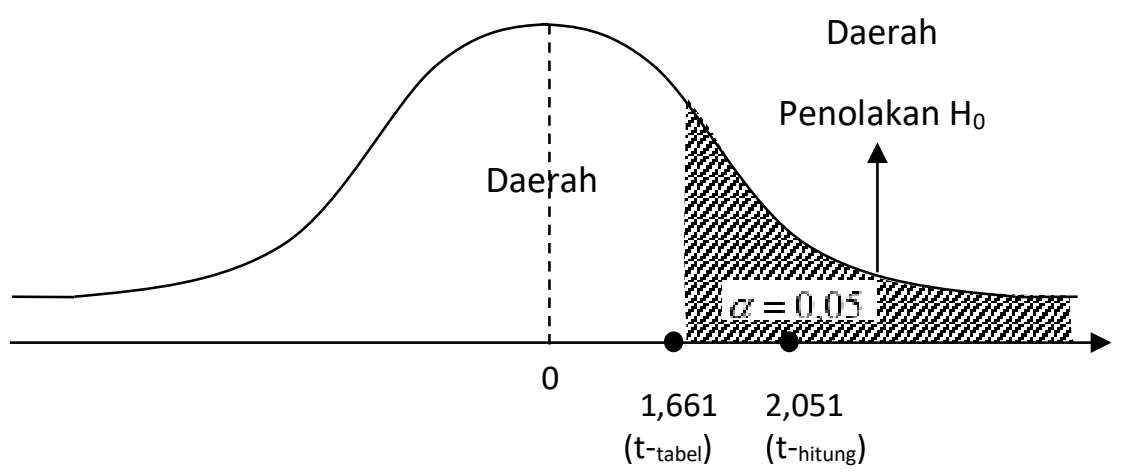

3. Pengaruh harga terhadap pembelian sepeda motor Honda Scoopy pada PT. Astra Internasional HSO. Tbk Honda Cabang Denpasar :

a. Perumusan hipotesis

$\mathrm{H}_{0}: \beta \mathrm{i}=0$ berarti tidak ada pengaruh yang signifikan antara kualitas produk (X1), merk (X2) dan harga (X3) terhadap pembelian sepeda motor Honda Scoopy (Y) pada Honda Scoopy pada PT. Astra International HSO

- Cabang Denpasar
Hi : $\beta \mathbf{i}>0$ berarti ada pengaruh yang signifikan secara parsial antara kualitas produk (X1), merk (X2) dan harga (X3) terhadap pembelian sepeda motor Honda Scoopy pada PT. Astra International HSO Cabang Denpasar.

Sesuai dengan hipotesis alternative ( $\mathrm{Hi}$ ) yang diajukan di atas, maka dalam pengujian ini digunakan uji sisi kanan dengan $\alpha=0,05$ dan $\mathrm{df}=\mathrm{n}-\mathrm{k}-1$. 
Pengaruh Kualitas Produk, Merk, dan Harga Terhadap Keputusan Pembelian Sepeda Motor Honda Scoopy Pada PT. Astra Internasional Honda Sales Operations Tbk. Honda Cabang

Denpasar

b. Membandingkan nilai t-hitung dengan nilai t-tabel, dengan kriteria sebagai berikut :

1) Jika t-hitung $\leq \mathrm{t}$-tabel, maka $\mathrm{H}_{0}$ diterima dan Hi ditolak.

2) Jika t-hitung $>$ t-tabel, maka $\mathrm{H}_{0}$ ditolak dan Hi diterima.

c. Perhitungan t-hitung

d. Berdasarkan gambar penerimaan dan penolakan Ho diatas ditentukan, nilai t hitung $=2,916$ lebih besar dari $\mathrm{t}$ tabel 1,661 dengan nilai signifikasi $=0,004$ lebih kecil dari 0,05 sehingga Ho ditolak dan $\mathrm{Ha}$ diterima. Ini berarti bahwa harga $\left(\mathrm{X}_{1}\right)$ konstan, secara statistika pada taraf kepercayaan 5\%, maka harga $\left(\mathrm{X}_{2}\right)$ berpengaruh positif dan signifikan terhadap keputusan pembelian (Y). Berartinya harga merupakan peran penting dalam meningkatkan penjualan sepeda motor Honda Scoopy pada PT. Astra International HSO Cabang Denpasar.

e. Menggambarkan daerah penerimaan dan penolakan hipotesis. Untuk mengetahui bahwa $\mathrm{H}_{0}$ diterima atau ditolak, maka digambarkan dalam kurva distribusi t sebagai berikut :

\section{Gambar 5.1.2}

\section{Daerah Penerimaan dan Penolakan $\mathrm{H}_{0}$ (t-test uji $\beta 3$ )}

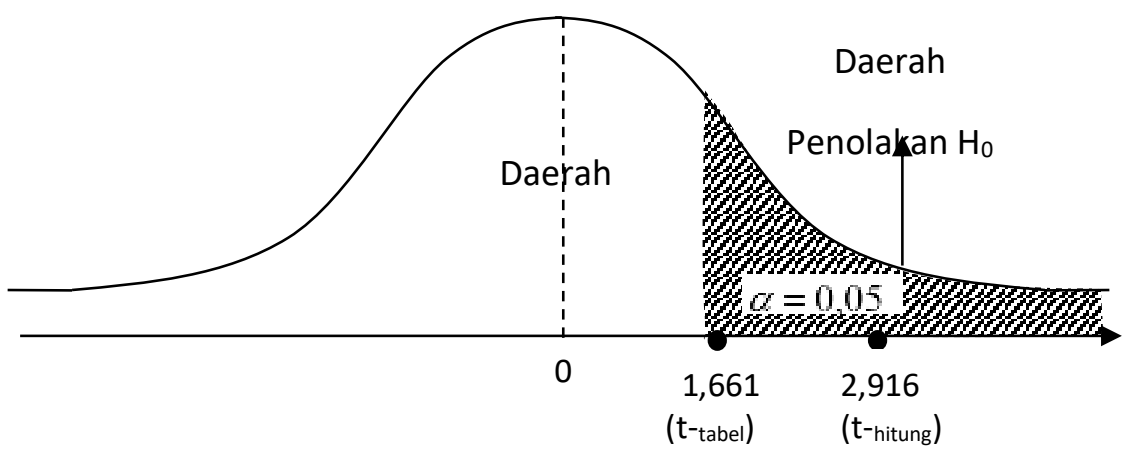

Uji F ( pengujian hipotesis secara simultan)

Untuk pengujian pengaruh variabel bebas secara bersama-sama terhadap variabel terikatnya dilakukan dengan menggunakan uji $\mathrm{F}$. hasil perhitingan SPSS menunjukkan nilai F-hitung = $14,725>$ F-tabel 2,700 tingkat signifikansi yang dihasilkan adalah sebesar 0.000 yang lebih kecil dari pada 0,05 , sehingga bisa dijelaskan bahwa $\mathrm{H} 0$ ditolak, Hi diterima. Artinya hipotesis $\mathrm{Hi}$ yang menyatakan bahwa kualitas produk, merk, dan harga memberikan pengaruh signifikan terhadap pembelian sepeda motor Honda Scoopy pada PT. Astra International HSO - Cabang Denpasar secara bersama-sama atau simultan dapat diterima.

\section{KESIMPULAN}

Dari data primer yang diperoleh dari penyebaran kuesioner maka dilakukan pengujian untuk mengetahui jawaban responden. Berdasarkan dari hasil analisis dan pembahasan yang telah 
diuraika, kualitas produk, merk, dan harga mempunyai pengaruh yang positif dan signifikan secara simultan terhadap keputusan pembelian. Dalam hal ini variabel harga berpangaruh lebih kuat karena harga mempunyai nilai koefisien regresi yang lebih tinggi dengan nilai sebesar 2,916 dibandingkan variabel yang lain. Hal ini menunjukkan harga memiliki peran yang sangat kuat yang paling berpengaruh untuk meningkatkan pembelian pada PT. Astra International HSO - Cabang Denpasar.

\section{SARAN}

Dilihat dari tingkat pembelian sepeda motor, Honda Scoopy terbukti memiliki harga yang mampu dijangkau oleh semua kalangan masyarakat. Oleh karena itu pihak perusahaan yaitu PT Astra International HSO Tbk. - Honda Cabang Denpasar hendaknya lebih memfokuskan penjualan produknya dengan selalu berinofasi menciptakan kualitas produk yang baik dari produk yang diproduksi khususnya kualitas produk yang inofatif terutama di bagian mesin sepeda motor Honda Scoopy. Hal ini dapat menarik minat konsumen untuk lebih yakin memiliki produk Honda tersebut. Selain itu hal yang dapat dilakukan oleh PT Astra International HSO Tbk. - Honda Cabang Denpasar, dengan menawarkan sistem pembayaran baik secara tunai maupun kredit serta memberikan potongan harga yang disesuaikan dengan tingkat pendapatan konsumen.

\section{DAFTAR PUSTAKA}

Ali Hasan. 2009. Marketing. Jakarta : Media Presindo.
Amstrong, Gary \& Philip, Kotler. 2002. Dasar-dasar Pemasaran. Jilid 1, Alih Bahasa Alexander Sindoro dan Benyamin Molan. Jakarta: Penerbit Prenhalindo.

Arief, 2007. Pemasaran Jasa \&Kualitas Pelayanan. Malang : Bayumedia

Publishing.

Basu Swastha, 2000, Pengantar Bisnis Modern, Pengantar Ekonomi Perusahaan Modern, Jakarta : Liberty.

Basu Swastha, Hani Handoko. 2011. Manajemen PemasaranAnalisis Perilaku Konsumen. Yogyakarta : BPFE.

Basu Swastha dan Ibnu Sukotjo, 2002, Pengantar Bisnis Modern, Edisi Ketiga, Yogyakarta: Liberty. 2002. Manajemen Pemasaran. Edisi Kedua. Cetakan Kedelapan. Jakarta: Penerbit Liberty.

Charles W. Lamb, Joseph F. Hair, Carl Mcdaniel. 2001. Pemasaran. Edisi Pertama, Salemba Empat, Jakarta.

Deliyanti Oentoro, Manajemen Pemasaran Modern. Yogyakarta: LaksBang PRESSindo, Juli 2012

Fandy, Tjiptono, 2000 .Manajemen Jasa, Andy, Yogyakarta. 
Pengaruh Kualitas Produk, Merk, dan Harga Terhadap Keputusan Pembelian Sepeda Motor Honda Scoopy Pada PT. Astra Internasional Honda Sales Operations Tbk. Honda Cabang

Denpasar

2008 ,

Strategi Pemasaran, Edisi 3, ANDI: Yogyakarta,

Husein Umar. 2013. Metode Penelitian untuk Skripsi dan Tesis. Jakarta: Rajawali

J, Paul Peter dan Olson, 2000, Perilaku Konsumen dan Strategi Pemasaran. Edisi 4, jilid 1. Erlangga, Jakarta.

Kotler, Philip, 2000, Manajemen Pemasaran, Edisi Milenium, Jakarta, Prehallindo.

2001. Manajemen Pemasaran : Analisis, Perencanaan, Implementasi, dan Kontrol. Jakarta : PT. Prehallindo

Kotler, Philip. 2002,Manajemen Pemasaran, Jilid 1, Edisi Milenium, Jakarta,

Prehallindo.

.2003. Manajemen

Pemasaran. edisi kesebelas, Jakarta: Indeks

kelompok Gramedia.

Pemasaran: Analisis, Perencanaan, implementasidan Kontrol, Edisi Sebelas. Alih Bahasa, Hendra Teguh.

Jakarta:

Penerbit

PT.Prenhallindo.

2005.Manajamen

Pemasaran, Jilid 1 dan 2.

Jakarta: PT. Indeks

Kelompok Gramedia.
2006. Principles of

Marketing. New Jersey:

Pearson Internasional

Edition.

. (2011). 10th Edition.

"Marketing an Introduction". Indonesia: Perason.

Muhamad Basir. (2016) "Pengaruh Ekuitas Merek Honda

Terhadap Keputusan

Konsumen Dalam Memilih

Sepeda Motor Pada PT.

Wiratama Multi Prima

Makassar (STIE-YPUP

Makassar)

Nur Achidah, M Mukery Warso Dan Leonardo Budi Hasiolan. 2016. " Pengaruh Promosi, Harga, dan Desain Terhadap Keputusan Pembelian Sepeda Motor Mio GT (Study Empiris Pada Produk Yamaha Mio GT Di WeleriKendal)

Novemy Triyandari Nugroho (2015)

"Analisis Pengaruh Kualitas

Produk, Harga, dan Promosi

Terhadap Keputusan

Pembelian AirMineral

Kemasan (Studi Kasus Desa

Tohudan, Colomadu

Karanganyar)

Simamora, Henry, 2004, Manajemen

Sumber Daya Manusia, Edisi

Ketiga,

Cetakan Pertama, Bagian

Penerbitan STIE YKPN, Yogyakarta.

Setiadi, Nugroho J. 2003, Perilaku Konsumen. Kencana. Jakarta. 
Stanton, W.J. dan L. Lamarto, 2001, Prinsip Pemasaran Jilid I, Erlangga, Jakarta.

- 2006. Manajemen Pemasaran Edisi 11. Jakarta: PT. Indeks

Sugiyono . 2004. Metode Penelitian Bisnis: Penerbit CV. Alfabeta: Bandung

— 2007, Metodologi Penelitian Bisnis, PT. Gramedia, Jakarta

Sugiyono . 2012. Memahami Penelitian Kualitatif. Bandung : ALFABETA. 2013. Metode Penelitian Kuantitatif Kualitatif dan $R$ \& D. Bandung : Alfabeta.

Sumarwan, U. 2004. Perilaku Konsumen : Teori dan Penerapannya dalam Pemasaran. Ghalia Indonesia, Bogor

Sofjan Assauri,. 2002. Manajemen Pemasaran (dalam konsep dan strategi), 